\title{
EL ARBOL APOSTOLICAL, PARTE DEL ARBOL DE LA CIENCIA, DE RAIMUNDO LULIO, EN UNA VERSIÓN CASTELLANA DEL SIGLO XV. INTRODUCCIÓN Y EDICIÓN DEL PRÓLOGO'
}

\author{
Klaus Reinhardt \\ Universidad de Trier (Alemania)
}

\section{RESUMEN}

El manuscrito 21-7 de la biblioteca capitular de Toledo contiene una versión castellana medieval, del siglo XV, del Arbor apostolicalis, parte del Arbor scientiae, de Raimundo Lulio. El presente artículo estudia la versión, hasta ahora desconocida entre los historiadores del lulismo, añadiendo una edición del prólogo, dirigido por un lulista anónimo al arzobispo de Toledo, probablemente Alfonso Carrillo.

Palabras clave: Raimundo Lulio, Arbol de la ciencia, Arbol apostolical, traducción castellana medieval.

\begin{abstract}
The manuscript 21-7 of the Cathedral Library of Toledo contains a medieval translation of the Arbor apostolicalis, part of the Arbor scientiae, of Ramon Lull, together with a preface addressed from a anonymous lulist to the archbishop of Toledo, probably Alfonso Carrillo. The article investigates the manuscript, ignored from the historians of the lulisme, and presents an edition of the preface.
\end{abstract}

Key words: Ramon Lull, Arbor scientiae, Arbor apostolicalis, medieval spanish translation.

La edición crítica del Arbor scientiae de Raimundo Lulio, aparecida en $2000,{ }^{2}$ y el congreso celebrado con motivo de este acontecimiento ${ }^{3}$ han confirmado una vez más la importancia de esta obra enciclopédica que Raimundo Lulio compuso durante los años 1295/96 en Roma. Ya en la edad media la obra obtuvo una considerable difusión. ${ }^{4}$ Del texto original latino se conocen hoy 17 manuscritos, copiados entre finales del siglo XIV y comienzos del XVI;

1 Agradezco de todo corazón a mis amigos Adeline Rucquoi, Nieves Baranda, Víctor Infantes y Ramón Gonzálvez que me han ayudado mucho en la investigación del manuscrito.

2 Raimundi Lulli opera latina 65: Arbor scientiae, Romae in festo sancti Michaelis archangeli anno MCCXCV incepta, in ipsa urbe Kalendis Aprilibus anni MCCXCVI ad finem perducta, lib. I-XVI. Ed. Pere Villalba Varneda. Turnhout 2000 (=CCCM 130A-C).

3 Arbor scientiae. Der Baum des Wissens von Ramon Lull. Akten des Internationalen Kongresses aus Anlaß des 40-jährigen Jubiläums des Raimundus-Lullus-Instituts der Universität Freiburg i.Br. Edd. Fernando Domínguez Reboiras, Pere Villalba Varneda y Peter Walter (Turnhout 2002).

4 Cf. P. Villalba Varneda, Introductio generalis, in: CCCM 130A, p. 1*-188*, en particular p. 179*-181*. 
los primeros impresos aparecieron en 1482 y 1505 en Barcelona. Ya temprano se hizo una traducción al catalán de la que se conocen dos manuscritos copiados a principios del siglo XV. ${ }^{5}$

En cambio, la primera traducción del Arbor scientiae al castellano es, según P. Villalba en su introducción a la edición crítica latina ${ }^{6}$, la de Alonso Zepeda y Adrada, aparecida en 1663 en Bruselas. ${ }^{7}$

Es cierto que la obra luliana llegó a difundirse en Castilla con bastante retraso. ${ }^{8}$ Sin embargo, Joaquín Carreras y Artau señaló ya en 1936 que se enumeran en el inventario del conde de Benavente, de hacia 1447, entre un gran número de obras lulianas dos ejemplares del Arbol de la ciencia; dado que el título se pone en castellano, hay que suponer que se trate de ejemplares de una versión castellana. ${ }^{9}$ Además sabemos que se encontraba un manuscrito de la versión latina del Arbor scientiae, copiado a principios del siglo XV, en la biblioteca del duque de Uceda. ${ }^{10}$

Con la presente aportación pretendemos llamar la atención de los historiadores del lulismo sobre el hecho de que la Biblioteca capitular de Toledo conserva en el manuscrito 21-7 una traducción castellana del siglo XV que ciertamente no contiene el Arbol de la ciencia en su to-

5 Milano, Ambrosiana D. 535 inf., (s. XV), escrito por Petrus Eximeneç de la Torre; el segundo manuscrito, copiado en Perpiñán en 1418 por Guillem Çavall (Savall) se ha perdido hoy. Edición crítica: Arbre de sciencia escrit a la ciutat de Roma l'any M.C.C.LXXXXV, ed. Salvador Galmés, 3 vols., Palma de Mallorca 1917-1923-1926 (= ORL XI-XIII).

6 Cf. P. Villalba, loc. cit. (nota 4).

7 Arbol de la Ciencia de el iluminado maestro Raymundo Lulio. Nuevamente traducido y explicado por el Teniente de Maestro de Campo General Don Alonso de Zepeda y Adrada, Governador de el Thol-huys, etc. En Bruselas, por Francisco Foppens, Impresor y Mercader de Libros 1663. Según el prólogo Zepeda no conocía ninguna traducción castellana anterior. Sobre Zepeda cf. Fernando Díaz Esteban, ,Entre la religión y la filosofía: la polémica de Isaac Orobio y Alonso de Zepeda', Sefarad 61 (2001) 319-344, 62 (2002) 21-55.

8 Sobre la historia del lulismo en Castilla cf. J. Carreras y Artau, ,Los comienzos del lulismo en Castilla“, Colección de estudios históricos, jurídicos, pedagógicos y literarios (Mélanges Altamira) (Madrid 1936) 65-72; J. y T. Carreras y Artau, Historia de la filosofía española. Historia de la filosofía cristiana de los siglos XIII al XV, vol. II (Madrid 1943); Idem, ,En torno al primer siglo del lulismo', Estudios Lulianos 22-23 (1964) 83-90; M. Cruz Hernández, El pensamiento de Ramon Llull (Valencia 1977) 301-355, especialmente 315-318; J. Perarnau i Espelt, „La traducció castellana medieval del Llibre de Meravelles de Ramon Llull", Arxiu de Textos Catalans Antics 4 (1985) 7-60; concretamente 7-17; id., ,El lul.lisme, de Mallorça a Castella a través de València', ibid. 61-172, en particular 89-90; J. N. Hillgarth, ,Lulismo', Diccionario de Historia Eclesiástica de España II (1972) 1361-1367; id., Readers and Books in Majorca, 1229-1550, 2 vols (Paris 1991); Lola Badia - Anthony Bonner, Ramón Llull: vida, pensamiento y obra literaria (Barcelona 1993) 213-228; F. Domínguez Reboiras, ,El Coment del dictat de Ramon Llull. Una traducción castellana de principios del siglo XV', Studia in honorem prof. M. de Riquer IV (Barcelona 1991) 169-232; Jordi Pardo Pastor, ,El lulismo hispánico del trescientos‘, A. Fidora - J. G. Higuera (eds.), Ramon Llull: caballero de la fe. El arte luliana y su proyección en la edad media (Pamplona 2001) 111-127; F. Gómez Redondo, Historia de la prosa medieval castellana III (Madrid 2002) 3359-3401 (Los orígenes de la ficción alegórica: la influencia del lulismo).

9 Cf. J. Carreras y Artau, Los comienzos (nota 8). Sobre el inventario del conde de Benavente véase además R. Beer, Handschriftenschätze Spaniens. Bericht über eine in den Jahren 1886-1888 durchgeführte Forschungsreise (repr. Amsterdam 1970) 103-109 (Benavente, Biblioteca particular del conde D. Rodrigo Alfonso Pimentel, n. 62 y 106); Isabel Beceiro Pita, ,Los libros que pertenecieron a los condes de Benavente, entre 1434 y $1530^{`}$, Hispania 43 (154) (1983) 238-280, p. 261-280 (edición del Inventario de los libros del tercer conde de Benavente); id., ,La Biblioteca del conde de Benavente a mediados del siglo XV y su relación con las mentalidades y usos nobiliarios de la época', Estudios en memoria del Profesor D. Salvador de Moxó I (Madrid 1982) 135-146, especialmente 142.

10 Hoy día el manuscrito se conserva en la BN de Madrid (MS 3364). Cf. Gregorio de Andrés, ,Catálogo de manuscritos de la biblioteca del Duque de Uceda', RABM 78 (1975) 5-40 (n. 670); P. Villalba, Introductio (como nota 4), p. 157*. Tenemos más noticias sobre existencias de obras lulianas en la España medieval. El marqués de Santillana, Iñigo López de Mendoza (1398-1458), conservaba en su biblioteca tales obras, también el convento de los jerónimos de Guadalupe poseía, gracias a donaciones de los años 1432 y 1445, varias obras de Raimundo Lulio, aunque no el Arbor scientiae. Cf. Guy Beaujouan, ,La bibliothèque et l'école médicale du monastère de Guadalu$\mathrm{pe}^{*}, \mathrm{G}$. Beaujouan - Yvonne Poulle-Drieux et Jeanne-Marie Dureau-Lapeyssonnie, Médicine humaine et vétérinaire à la fin du Moyen Age (Genève-Paris 1966) 367-468, particularmente p. 386-387, 426, 428-429. Cf. también M. Schiff, La Bibliothèque du Marquis de Santillane (Paris 1905). 
talidad, pero sí una parte, el Arbol apostolical, junto con el prólogo de un lulista anónimo, prólogo dedicado a un arzobispo, probablemente el de Toledo. Es una obra interesantísima bajo varios puntos de vista, codicológico, filológico e histórico. Al mismo tiempo es un escrito enigmático lleno de alusiones, pero sin revelar nombre ninguno, ni el del arzobispo, ni el del prologuista ni siquiera el del autor del Arbol apostolical, incitando con esto la curiosidad y el instinto cazador del investigador.

\section{DESCRIPCIÓN DEL MANUSCRITO 21-7 DE LA BIBLIOTECA CAPITULAR DE TOLEDO}

\subsection{Descripción externa}

Dos folios antepuestos no numerados en blanco, 58 folios numerados, f. $53 \mathrm{v}-58 \mathrm{r}$ en blanco. 24 x 16,2 cm. Dos columnas. 30 líneas. Reenvíos al folio siguiente en los folios $12 \mathrm{vb}, 24 \mathrm{vb}$ y $48 \mathrm{vb}$; en f. $14 \mathrm{v}$ solamente una , $\mathrm{s}^{6}$ (?). Una nota marginal en f. 3ra. Dos citas bíblicas (del evangelio de San Mateo) latinas en el prólogo (f. 2ra) han sido introducidas por una mano posterior con tinta diferente. Capitales (iniciales) en rojo y azul. Calderones en rojo.

Papel, con marcas de agua en forma de tijeras. Las tijeras están cortadas de manera que una parte, el asidero y el comienzo de las piernas, se encuentran en los folios $11,12,20,23$, $24,26,29,30,39,41,43$ y 48 y la continuación de las tijeras, las piernas, en los folios 1,2 , $6,13,14,17,31,32,35,37,42,44,46,52$. El papel, así marcado, procede de fábricas de Italia del Norte, de Liguria, y fue utilizado durante todo el siglo XV. Oriol Valls i Subirà conoce solamente cuatro incunables y manuscritos confeccionados en España que utilizan un papel de marca similar, tres incunables impresos en 1477 y 1482 en Valencia por el alemán Lamberto Palmart, y un manuscrito con correspondencia de los jerónimos de Guadalupe, fechado en 1485. ${ }^{11}$ No obstante, los ejemplos presentados por Valls i Subirà no nos dan un indicio seguro para la datación, primero porque por lo menos las marcas de los incunables no corresponden exactamente a las del manuscrito toledano, añadiendo encima de las tijeras una lineta curva o una estrella. Además, parece muy inverosímil que exista en toda España sólo uno o a lo más cuatro ejemplos de este tipo de papel, ya que Gerhard Piccard enumera para Europa central y oriental 343 ejemplos de papel marcado con tijeras de los que unos 123 coinciden más o menos con el papel del manuscrito toledano; estos ejemplos están fechados entre 1410 y 1502; en su mayoría pertenecen a la segunda mitad del siglo XV..$^{12}$

La escritura parece ser de la primera mitad del siglo XV.

Encuadernación mudéjar del siglo XV.

De estos datos no se puede deducir una datación exacta del manuscrito. Es seguramente del siglo $\mathrm{XV}$, quizás de mediados del siglo, sin que se pueda excluir una datación más temprana.

11 Cf. Oriol Valls i Subirà, La historia del papel en España. II: Siglos XV-XVI (Madrid 1980) n. 250-253, p. 169-170 (texto), 241-242 (filigranas). Cf. también Charles-Moïse Briquet, Les Filigranes. Dictionaire historique des marques du papier dès leur apparition vers 1282 jusqu'en 1600. II (Paris 1907) n. 3663, 3668, 3670. Gonzalo Gayoso Carreira, Historia del papel en España I-III (Lugo 1994) se centra en la época moderna.

12 Véase Wasserzeichen. Werkzeuge und Waffen. Teil 1. Text. Abbildungen I-V. Bearbeitet von Gerhard Piccard (=Veröffentlichungen der Staatlichen Archivverwaltung Baden-Württemberg... Sonderreihe: Die Wasserzeichenkartei Piccard im Hauptstaatsarchiv Stuttgart. Findbuch IX. Teil) (Stuttgart 1980) n. 651-994, p. 26-29 y 138161. Tijeras que coinciden más o menos con las de Toledo: n. 796-919, p. 141-154. Un ejemplo con tijeras cortadas en el medio se encuentra en n. 890 (p. 151), un manuscrito de Wezna (Lituania) de 1434. 


\subsection{Descripción interna}

El manuscrito no lleva título. De mano posterior se puede leer en la margen superior del folio 1r y al tejuelo: «Arbor apostolicalis ad Archiepiscopum Toletanum». El códice consta de tres partes:

1) f. 1ra-6rb: prólogo de un clérigo anónimo, dirigido a su arzobispo

2) f. 6ra-53rb: Versión castellana del Arbor apostolicalis junto con las cuestiones correspondientes del Arbor quaestionalis. Inc: «Del arbol apostolical. El arbol apostolical es departido en siete partes..». Expl: «que sea su senblança en el apostoligo. Explicit arbor apostolicalis».

3) Dos notas finales: la primera en f. 53rb; tapada por un papelito pegado encima: «Aquí se pone la escusación de non enbiar el arbor exemplifical que fue prometido por quanto el escrivano que fizo esta letra se hovo de ausentar de la tierra. Mas si fuere demandado muy presto se podrá embiar. Nunc autem excusationem non habent audientes de peccato suo ${ }^{13}$. Ea vero que hodie in clero et populo corrigenda, regenda et gubernanda sunt, non potest humana lingua retexere. Sed quia plenus sum sermonibus et coartat me spiritus uteri mei. Venter enim meus quasi mustum absque spiraculo quod lagunculas novas disrumpit. Loquar et respirabo paululum. Iob $32^{14}$. In quibus adiuvante Domino per brevia capitula illius (illis?) mihi vester ordo rreddendus».

Los folios 53v, 54r-58r están en blanco. En f. 58v se encuentra una segunda nota: «Absentose el escrivano de la tierra e por eso non se embía el arbor exemplifical. Mas prométese de embiar quando oviere lugar et tiempo de escrevir». La nota está firmada con el signo: «j.d». (d como el signo, deleatur').

\section{ANÁLISIS DEL CONTENIDO}

\subsection{El modelo de la traducción castellana: el Arbor apostolicalis de Raimundo Lulio}

No cabe duda que los folios $6 \mathrm{r}-53 \mathrm{r}$ contienen ùna traducción castellana del Arbor apostolicalis que constituye una parte del Arbor scientiae, compuesto por Raimundo Lulio en Roma en 1295/96. En el prólogo del Arbor scientiae el autor mismo describe la situación que le impulsó a la composición de esta obra. Desconsolado por el rechazo de su Ars de parte de los papas y cardenales, intentó a petición de un ermitaño presentar su sistema del saber de una manera más gráfica y accesible, utilizando la imagen del árbol. ${ }^{15} \mathrm{El}$ Arbor scientiae luliano consta de 16 árboles. 14 de ellos tratan los diversos grados del universo, desde el más ínfimo de los elementos (Arbor elementalis) hasta el supremo que es Dios (Arbor divinalis). Los dos últimos árboles, el Arbor exemplificalis y el Arbor quaestionalis se refieren a los 14 árboles antecedentes, aclarándolos con ejemplos y cuestiones.

El Arbor apostolicalis, que es el octavo de los 16 árboles, ${ }^{16}$ trata del orden del mundo espiritual y eclesiástico. Como todos los árboles, también el Arbol apostolical está dividida en

13 Io 15,22

14 Iob $32,18-20$

15 Sobre la situación del desconsuelo de Raimundo y la relación entre el poema autobiográfico Desconort y el Arbor scientiae cf. Vittorio Hösle, ,Rationalismus, Intersubjektivität und Einsamkeit: Lulls Desconort zwischen Heraklit und Nietzsche', Constantes y fragmentos del pensamiento luliano. Actas del simposio sobre Ramon Llull en Trujillo, 17-20 septiembre 1994. Ed. Femando Domínguez y Jaime de Salas (Tübingen 1996) 39-57.

16 Cf. Francesco Santi, ,Arbor apostolicalis. La vita dell'organismo apostolico', Arbor scientiae (como nota 3) $197-205$. 
siete partes: raíces, tronco, ramas, ramos, hojas, flores y fruto. Las raíces son las cuatro virtudes cardenales y las tres teologales. El tronco es el papa, llamado el apostólico. Las ramas son las autoridades eclesiásticas desde los cardenales hasta los simples sacerdotes. Los ramos son los preceptos, las hojas los siete sacramentos y los cánones de la iglesia, las flores los catorce artículos de la fe y el fruto la salvación eterna.

Esta breve relación sobre el origen y la estructura del Arbor scientiae, que Raimundo Lulio da en el proemio de su obra, la encontramos abreviada y romanceada en el prólogo del manuscrito de Toledo (n. 10-12). Respecto al texto del Arbor apostolicalis, el manuscrito de Toledo se destaca por una peculiaridad significante; y es que saca del Arbor quaestionalis las cuestiones que se refieren al Arbor apostolicalis y las intercala en su lugar correspondiente en el Arbor apostolicalis. Esta reorganización de los textos parece ser única que no se encuentra en ningún otro manuscrito conocido, tanto latino como catalán. ${ }^{17}$ No se sabe, si fue el traductor quien introdujo esta novedad o si la adoptó de su modelo. Evidentemente el prologuista del manuscrito de Toledo se dio cuenta de esto al decir que el Arbol cuestional se encuentra «enexerido e derramado por todos los otros» (n. 14).

\subsection{El autor del Arbor apostolicalis, Raimundo Lulio, a la luz del manuscrito de Toledo}

Sorprende que el manuscrito de Toledo no da nunca el nombre del autor del Arbor apostolicalis. El prólogo habla de una «obra muy nueva» (n. 9) y de un «actor de sciencia nuevo» (n. 10). ,Nuevo' significa en este contexto primeramente , hasta ahora desconocido', lo que es confirmado, según el prólogo, por el hecho de que existían hasta entonces sólo dos ejemplares del Arbor scientiae en toda la archidiócesis (de Toledo). Respecto al contenido, la novedad del Arbol de la ciencia consiste según el prólogo en el hecho de que el autor del Arbol no se basa en autoridades sino que procura demostrar las verdades de la fe mediante argumentos racionales.

La novedad del pensamiento luliano de la que habla el prólogo no puede significar que el manuscrito de Toledo fuera escrito poco después de la composición del Arbor scientiae (1295/96) o poco después de la muerte de su autor (ca. 1315/16); esta novedad debe ser referida a la infiltración del lulismo en Castilla. Es cierto que ya el Infante Don Juan Manuel utilizaba en su Libro del cavallero et del escudero (1326) el Llibre del orde de la cavayleria de Raimundo Lulio; sin embargo en general las obras lulianas se conocieron en Castilla sólo a partir de la primera mitad del siglo XV, como lo demuestran, entre otros, los inventarios de la biblioteca del convento de los jerónimos en Guadalupe de 1435 y de la biblioteca del conde de Benavente de hacia $1447 .{ }^{18} \mathrm{Si}$ los dos ejemplares del Arbol de la ciencia existentes en la biblioteca del conde de Benavente tienen algo que ver con los dos ejemplares señalados en el prólogo del manuscrito de Toledo como existentes en el arzobispado (de Toledo), no se puede decir con seguridad; de todas formas el hecho de que Benavente no pertenecía a la archidiócesis de Toledo no está en contra de una suposición afirmativa, ya que los dos ejemplares podrían haberse encontrado antes de su adquisición por el conde de Benavente en un convento franciscano o jeronimiano situado en el territorio de la archidiócesis de Toledo.

En todo caso hay que fechar el manuscrito de Toledo en los años en que se iban infiltrando las ideas lulianas en Castilla. No extraña que el manuscrito no mencione el nombre de Raimundo Lulio. Aunque la bula del papa Gregorio XI de 1376, que prohibió varias obras de Rai-

17 Más tarde, también Alonso de Zepeda (como nota 6) reorganizó el orden de los apartados, pero solamente dentro del Arbor exemplificalis y del Arbor quaestionalis, dividiendo todo según los diversos árboles (árbol elemental etc.) y no, como las versiones latina y catalana, según las partes de los árboles (raíces, tronco etc.).

18 Cf. la bibliografía citada en la nota 5. 
mundo Lulio por contener sentencias heréticas, había sido declarada sin validez por la llamada Sententia definitiva de 1419, muchos autores del siglo XV siguiendo ideas lulianas prefirieron no mencionar el nombre de este doctor nuevo. ${ }^{19}$

\subsection{La traducción castellana en comparación con las versiones latina y catalana}

Respecto a la traducción castellana del Arbol apostolical se plantean varias preguntas: ¿Quién es el traductor? ¿Cuándo se hizo la traducción? ¿Y sobre qué texto, el latino o el catalán? Y, por fin, ¿cuál es el estilo de la traducción?

En todo caso podemos afirmar que el autor del prólogo del manuscrito toledano no es el traductor. Como él mismo dice en el prólogo (n. 9), encontró en el arzobispado de Toledo ya dos ejemplares del Arbol de la ciencia «en romance»; de la conclusión del prólogo incluso se puede deducir que consideró la versión «en romance» (n. 16) no como traducción sino como la versión original. El trabajo del prologuista consistía sólo en sacar dos árboles del cuerpo del Arbol de la ciencia, es decir, el Arbol apostolical y el Arbol ejemplifical (n. 13) y en pedir a un escribano que las copiase para que pudiera enviarlas al arzobispo; desgraciadamente el escribano no llegó a copiar el Arbol ejemplifical. ${ }^{20}$

Respecto a la traducción se plantea el problema de en qué texto se basa, en el texto latino o el catalán.

Hay puntos en que coincide la versión castellana con la catalana y en que se distinguen las dos de la latina. Por ejemplo, ambas versiones suelen introducir las cuestiones del Arbol cuestional como cuestiones de un ermitaño, mientras que el texto latino hace esto en algunos casos, pero en otros utiliza el pasivo evitando de esta manera a mencionar a la persona que plantea la cuestión. ${ }^{21}$

Por otra parte existen diferencias notables entre la versión catalana y la castellana. Mientras que el texto catalán traduce la palabra latina ,brancae' con ,branques', el manuscrito de Toledo pone siempre ,ramas'. Otro ejemplo son las palabras latinas «et etiam (litterae pulchrae sunt)» (CCCM 180B, p. 377, lin. 13), traducidas al castellano «et aunn que (las letras son fermosas)» (MS Toledo f. 6rb, lin. 6), mientras que la traducción al catalán pone «e encara, que». Además, como ya queda dicho, la versión castellana de Toledo se distingue tanto de la versión catalana como de la latina por intercalar las cuestiones del Arbol cuestional en el Arbol apostolical. ${ }^{22}$

Resumiendo se puede decir que la traducción castellana no depende de la catalana, aunque tiene algo común con ella.

En cuanto a las formas lingüísticas hay que distinguir entre el prólogo y la traducción. Podemos señalar aquí solamente algunas peculiaridades del prólogo, dejando para un trabajo posterior la edición y el estudio de la traducción. Las formas ,ayaes, vees, recibaes, soes, estaes", habituales en el prólogo del texto toledano, son propias de finales del XIV y principios del $\mathrm{XV} .{ }^{23}$ Llama la atención también el seseo (selo por zelo, sagas por sagaz, desir por decir) en el autor o en el copista aunque no es general. Otra peculiaridad característica del prólogo son los muchos latinismos; casi todas las citas están en latín; además dentro del texto castellano aparecen no pocas expresiones latinas.

19 Cf. Nicolás de Cusa en su obra De concordantia catholica.

20 Cf. las notas finales, f. $53 \mathrm{rb}$ y $58 \mathrm{v}$.

21 MS Toledo, f. 9vb (como la versión catalana): „Question: Soberano obispo, dixo el hermitanno, quales son las tus ramas». En cambio, el texto latino utiliza el pasivo: „Quaestio. Quaerebatur a summo pontifice seu a papa quales erant suae brancae». (CCCM 180C, p. 1030, n. 841).

22 Cf. nota 17.

23 Cf. R. Lapesa en un artículo de la Asociación Internacional de Hispanistas de México (p. 513-29, concretamente en p. 525), donde remite a un artículo de Cuervo, Romania 1893. 


\subsection{La labor del escribano}

Aunque el prólogo y la traducción del Arbol apostolical ofrecen diferencias linguíisticas, fueron copiados por una única mano, mientras que las notas finales parecen ser de otra mano, quizás del director del escritorio o del superior del convento, al que pertenecía el escribano. Lamentablemente no logramos a descifrar las siglas «j.d». que indican probablemente a esta persona. ${ }^{24}$ Tampoco se sabe, por qué la primera nota fue tapada por un papelito. A lo mejor, los folios blancos entre f. 53rb y 58ra quedaron reservados para el Arbol ejemplifical que ha sido prometido, pero no enviado por la ausencia del escribano.

Evidentemente, el escribano no trabajaba muy bien. Se notan varias negligencias. Por ejemplo, en f. 6ra, en la enumeración de las siete partes del árbol el copista olvida una, la parte de los ramos o ramuchos (cf. f. 4rb). Otro ejemplo: en f. 9ra el escribano pone en lugar de 'ramas' del Arbol 'armas'. ${ }^{25}$

\subsection{El prólogo: su autor y su destinatario}

Preguntemos al final de esta introducción por el destinatario de la obra y el autor de la dedicatoria. Estas son sin duda las preguntas decisivas para la comprensión de la obra.

El destinatario es según el prólogo un arzobispo español que ocupa una de las segundas sillas o sedes episcopales después de la romana (n. 2 y 14). Según el título añadido por una mano posterior se trata del arzobispo de Toledo, lo que es confirmado también por la presencia del manuscrito en la biblioteca capitular de Toledo. ¿Pero de qué arzobispo de Toledo se trata? El prólogo dibuja el retrato de un personaje polifacético y contradictorio; lo describe como un gran prelado en la iglesia y al mismo tiempo como un poderoso señor en el mundo (n. 2,3 y 14). El prologuista le reprocha que se cuide mucho de las cosas mundanas y muy poco de la salvación del alma suya y de las de sus súbditos (n. 3); su preocupación de las cosas del mundo se refiere además sólo a su propio provecho, a una vida de lujo, mientras que sus súbditos mueren de hambre y de frío (n. 3 y 14). Otro rasgo de la figura del arzobispo lo constituye su alto grado de erudición. Es un gran letrado, rodeado de muchos letrados, poseedor de muchos libros sobre la Sagrada Escritura (n. 5). Pero, ¿qué aprovecha una gran biblioteca, si los libros se cubren de polvo? (n. 5). Y, ¿qué aprovecha la asistencia de muchos letrados, si ellos son lisonjeros y malos consejeros? (n. 14) ${ }^{26} \mathrm{El}$ autor del prólogo reconoce la buena voluntad del arzobispo de reformar a la iglesia, al clero y a sí mismo; pero lo reprende por no llevar a efecto sus buenos deseos (n. 7).

La verdadera raíz de todo este mal la ve el autor del prólogo en el hecho de que se ha desatendido en su tiempo uno de los artículos de la fe, la fe en el juicio extremo y la vida eterna. Por eso, el prologuista recuerda constantemente al arzobipso el riesgo de la damnación eterna para él mismo y para sus súbditos. Como remedio para salvarse de la situación precaria le recomienda la lectura del libro de Raimundo Lulio, el Arbol apostolical, y como suplemento el Arbol ejemplifical. En este libro conocerá como en un espejo, cómo se salva o condena (n. 9). «Un ombre bien letrado, subtil de entendimiento e persona espiritual» (n. 13) debe leer al arzobispo dos o tres veces el texto y explicarle pasajes difíciles. El consejo de no detenerse mucho en las hojas y flores del Arbol apostolical (n. 13) no extraña, ya que estos apartados tratan muchas cuestiones especulativas. Lo que cuenta a los ojos del prologuista no es la erudición y la especulación sino la práctica espiritual.

24 Cf. la descripción externa, n. 1.1.

25 Más ejemplos pueden verse en f. 7va (Más es el perlado por caridat que por criar (en lugar de cremar) herejes; f. 11ra: A sant Pedro apostol (texto latino: sancto patri apostolico; catal.: a sant pare apostoli).

26 Cf. también n. 8: «Nunca tantos letrados ovo después que crió Dios el mundo como oy día». 
El autor del prólogo era, como él mismo dice, clérigo de la archidiócesis (de Toledo) (n. 2). A sus confesiones de humildad y reverencia hacia su arzobispo corresponde por otra parte una conciencia de sí muy fuerte y casi exagerada, como se desprende sobre todo de la conclusión del prólogo: «no escribí como un siervo al dueño, un súbdito al prelado ni siquiera como un hijo al padre, sino... como una criatura a otra criatura, como un hombre a otro hombre, como Platón a Cicerón». (n. 15).

Evidentemente el autor del prólogo era un lulista decidido, convencido de que sólo las ideas lulianas podrían conducir a una reforma espiritual de la iglesia. A lo mejor este lulista anónimo está vinculado con el así llamado lulismo espiritual de Valencia, cultivado sobre todo en la «Escuela de Alcoy» donde enseñó hacia 1369 con mucho éxito el fraile «menor» fray Pere Rosell $^{27}$, lulismo que se extendía desde Valencia hacia Mallorca, Cataluña y Castilla.

¿Quién es el arzobispo de Toledo a quien se dirige el lulista anónimo? El que mejor encaja con la descripción del prólogo es sin duda Alfonso Carrillo de Acuña, arzobispo de Toledo de 1446 a $1482 .{ }^{28}$ Era un personaje polifacético, ante todo fue un político, que apoyó a Juan II, luego a Enrique IV, y se pasó posteriormente al bando de Alfonso y de Isabel. Por otro lado estaba apasionado por las ciencias, en particular por la alquimia, y se rodeaba con poetas y letrados. Varios le dedicaron sus obras: Pedro de Huete (Petrus Optensis) en 1455 su Splendor fidei, una declaración de los artículos de la fe, ${ }^{29}$ Alfonso de Toledo en 1467 su Invencionario. ${ }^{30}$ Ya Fernando del Pulgar en su libro de los Claros Varones de Castilla destaca la ambigüidad de sus deseos y actividades:

«Era omme de gran coraçon e su principal deseo era fazer grandes cosas por aver fama e gran renombre. Tenía en su casa letrados e caballeros e ommes de fación. Rescibía muy bien e honrraba mucho a los que a él venían e tratábalos con buena gracia e mandávales dar gran abundancia de manjares de diversas maneras... cuanto era amado de algunos por ser franco, tanto era desamado por muchos por ser belicoso, seyendo obligado a religion». ${ }^{31}$

Más dura es la crítica que dedica fray Iñigo de Mendoza en sus Coplas de Vita Christi, escritas hacia 1467/68, al primado de Toledo:

«... Guay de vos, nuestro primado, / ; ay, don Alonso Carrillo! / porquel favor del estado / vos faze muy alongado / del pesebre pobrecillo: / vuestros costosos manjares, / vuestros francos beneficios, / a las personas seglares / son virtudes singulares, / mas en el cielo son vicios..».

Por otra parte se atribuye a don Alfonso Carrillo el mérito de haber iniciado en el concilio provincial de Aranda de Duero de 1473 la reforma eclesiástica en España.

Resumiendo se puede decir que la imagen de Alfonso Carrillo como lo dibujan los historiadores antiguos y modernos corresponde bien a la descripción del arzobispo del prólogo. ¿Está desvelado pues el enigma del manuscrito de Toledo? Quedan dudas. Ante todo los enunciados sobre la novedad del lulismo en Toledo y Castilla hacen pensar en un arzobispo anterior. Las calificaciones del arzobispo como letrado, rodeado de letrados y posesor de muchos

27 Cf. M. Cruz Hernández, El pensamiento (como nota 5) 315-318; J. Pardo, El lulismo hispánico (como nota 5) $116-127$.

28 De la abundante bibliografía sobre Alfonso Carrillo cf. Juan Francisco Rivera Recio, Los arzobispos de Toledo en la baja Edad Media (s. XII-XV) (Toledo 1969) 119-122; Pedro M. Cátedra, "Tratado que hizo Alarcón», alquimista del arzobispo Alonso Carrillo. Edición y estudio de P. M. Cátedra (Salamanca 2002).

29 Cf. K. Reinhardt, Pedro de Osma y su comentario al símbolo „Quicumque» (Madrid 1977) 39-40.

30 Alfonso de Toledo, Invencionario, ed. by Philip O. Gericke. Madison, Hispanic Seminary of Medieval Studies, 1992.

31 Fernando del Pulgar, Claros Varones de Castilla, citado según J. F. Rivera Recio, op. cit., p. 120-122. 
libros podrían aplicarse ya a Pedro Tenorio (1377-1399). ${ }^{32}$ También posteriores arzobispos son posibles candidatos del enigmático arzobispo del prólogo. A lo mejor la extraña expresión del prólogo «todo es vano quanto se faze debaxo de la luna (isic!)» (n. 9) podría ser una alusión encubierta al arzobispo Pedro de Luna (1403-1414) o a su sucesor Juan Martínez de Contreras (1423-1434), protegido por Pedro y por Álvaro de Luna; por otro lado estos dos prelados no son conocidos precisamente por su pasión por las letras y ciencias, pero sí por su vida mundana. La crítica a los prelados que se ve en el prólogo tiene una larga tradición en la España medieval. La encontramos en la poesía, por ejemplo en el poema Rimado de Palacio de Pedro López de Ayala (1332-1407) y luego en los versos de Alfonso Álvarez de Villasandino (ca. 1350-1424), coleccionados en el Cancionero de Baena (1445-1453). ${ }^{33}$ En el campo de la prosa hay que mencionar el Libro de los gatos; una sátira moralizante que fue escrita probablemente hacia el año $1400 .{ }^{34}$ Sin embargo, parecidos entre la crítica social y eclesiástica contenida en tales obras por una parte y la de nuestro prólogo por otra no conducen necesariamente a la identificación del arzobispo. Así queda como solución más probable la hipótesis de que el arzobispo de Toledo descrito allí sea Alfonso Carrillo al que un lulista manda un ejemplar del Arbol apostolical para incitarle a una reforma espiritual de la iglesia.

\section{EDICIÓN DEL PRÓLOGO}

Se respeta en general la grafía original. Excepciones: la u consonante se escribe como una v. Los nomina sacra van en mayúsculas. La separación entre por y que y entre libre y mente se quita en favor de la lección porque y libremente.

La acentuación es nuestra. La puntuación se ha modernizado. Respetamos los calderones continuando después de un calderón con una mayúscula, aunque no empieza una frase nueva. ${ }^{35}$

Las abreviaturas se resuelven. La lineta traversal superpuesta después de la $\mathrm{h}$ (por ejemplo en ,mucho") o sobre ,grand 'no se tiene en cuenta, considerándola como una extensión supérflua. ${ }^{36}$

Klaus Reinhardt

(1) Porque quecumque scripta sunt, ad nostram doctrinam scripta sunt, <ad > Romanos $15^{37}$. E dise el salmo ${ }^{38}$ quod Dominus prospexit de celo super filios hominum ut videat si est intelligens aut requirens Deum. E porque nichil prodest homini, si totum mundum lucretur, anime sue detrimentum paciatur, Matei $16 .{ }^{39} \mathrm{E}$ porque dormierunt somnum suum et nichil invenerunt omnes viri diviciarum in manibus suis ${ }^{40}$, ideo quia Deus suus vendidit eos, Deutero. $32 .{ }^{41}$ E porque sic nos existimet homo sicut ministros Christi et dispensatores ministeriorum

32 Cf. Fernán Pérez de Guzmán, Generaciones y semblanzas. Edición de José Antonio Barrio Sánchez (Madrid 1998) 112-114.

33 Cf. K. R. Scholberg, Sátira e invectiva en la España medieval (Madrid: Gredos, 1971) pp. 228 y ss. y pp. 269 y ss. En el Cancionero de Baena se notan influencias lulianas.

34 Libro de los gatos. Edition avec introduction et notes par Bernard Darbord. Paris 1984.

35 Cf. Pedro Sánchez-Prieto Borja, Cómo editar los textos medievales. Criterios para su presentación gráfi$c a$ (Madrid 1998) 183: «El calderón (ID) es marca de pausa mayor (en las versiones bíblicas generalmente coincide con el versículo, aunque ni mucho menos se marcan todos los versículos con este signo), en conjunción con (.) o con (.) y (M). Su apogeo se da en la libraria del siglo XIII. La ley de la cursividad desterró el signo (II) de la mayoría de los códices del siglo XV. El (.) de por sí no indica necesariamente pausa».

36 Cf. ibidem p. 92 y 93.

37 Rm 15,4

38 Ps 13,2

39 Cf. Mt 16,26

40 Ps 75,6

41 Dt 32,30 
(sic!) Dei. $\mathrm{I}^{\mathrm{a}}<\mathrm{ad}>$ Corinthios c. $4^{\circ 42}$, non tamen sicut devorantes plebem eius sicut escam panis $^{43}$. E porque no seamos sicut equus et mulus in quibus non est intellectus. ${ }^{44}$ E porque super quinque talenta que recibimos lucremur alia quinque y no cavemos en la tierra et abscondamus talentum unum. Matei $25^{45}$. E por otras muchas actoridades semejantes de la sagrada escriptura.

(2) | (f. 1rb) Muy magnífico sennor en la tierra e grand perlado en la eglesia de Dios, seedor sobre una de las sus segundas sillas, apaçentador e guiador de muchos millares o cuentos de ánimas, dador cuenta de la más menor de todas ellas. Ezech. $34^{46}$.

Yo, sennor, un pobrezillo de virtudes, clérigo de vuestro arçobispado, quamvis sim vermis, ymo vermiculus, et non homo ${ }^{47}$, para besar vuestros pies, no con sobrada njn elata presunçión, njn menos con vano estudio de mostrarme lisonjero fablador e mucho menos con loca osadía de corregir vida agena. Mas con quanta e qual reverençia yo puedo e devo, dexando la elegançia de las palabras, inçitado e conpellido con un dicho del Gregorio sobre el Ezechiel que dise: «quoniam nullum omnipotenti Deo tale sacrificium quale est zelus animarum». ${ }^{48}$

Desseando primeramente que Dios sea honrrado, magnificado, bendezido e alabado de sus criaturas raçionales (|f. 1va), después desseando e sin medida affectando la salvaçión de vuestra ánima e de todas las otras ánimas del pueblo a vos encomendado. E commo dise un sabio: «ubi maius periculum inminet, ibi velocius et caucius succurrendum est ${ }^{49}$

(3) E porque así commo nemo potest duobus dominis servire. Math. $6^{50}$, así vos, sennor, no podes vacar njn rregir el pueblo secular e eclesiástico e dar cuenta de todo, porque así commo son dos estados, así son dos governadores e rectores. Sed unum est necessarium, et vos optimam partem elegistis. Luce $10^{51}$, y vos fue encomendada: ego elegi vos et posui vos ut fructum afferatis et fructus vester maneat. Iohannis $15^{52}$. Desto avéis de dar cuenta e no de aquello, que allá ay otro pastor que la dará.

E commo desde que la silla tomastes, muy magnífico sennor, fasta oy, segund paresce por esperiençia, non solícita e cuydadosamente ayaes apasçentado estas encomendadas oves, porque mueren (|f. $1 \mathrm{vb}$ ) de fanbre, njn tanpoco las ayaes munido njn çercado de alto muro, porque cada una se sale del corral e va por do quiere e come resalgas ${ }^{53}$ e muere, njn menos ayaes puesto industriosos rabadanes con ligeros mastines en çerco e derredor por donde han lugar los lobos e rraposos e aún ossos de entrar sin alguna resistençia e faser, quando los zagales duermen, farto estrago e destroço en la manada, e lo peor que es que algunas vezes los mayorales velan e los veen venir e callan o fuyen.

(4) E porque es inpossible vos, sennor, passar sin dar estrecha cuenta con pago usque ad ultimum, e porque es grand dolor de veer tantas ánimas de christianos yr al infierno por vuestra culpa, y porque más vale tarde que nunca, y porque va mucho en ello, y porque es muy grand mal rrecabdo dexar perder un ánima, quánto más tantas, y porque el danno es común a muchos, y porque dies Domini sicut fur ${ }^{54}$ y porque el tal danno después | (f. 2ra) de conosçi-

Ps 31,9

Cf. Mt 25,20

Ez 34

Cf. Ps 21,7

Gregorius Magnus, Homilia in Ezech., lib. I, hom. 12, lin. 578: CCSL 142.

No hemos identificado la cita. Cf. también n. 59.

Mt 6,24.

Lc 10,42

Io 15,16

El texto dice ,resalgar‘. Al parecer la resalga es la sal que se da al ganado.

I Th 5,2 
do, scilicet después de la muerte es inrreparable que non lleva algund rremedio, porque solamente en este siglo es estado de meresçer o de desmereçer.

E porque, sennor, es nesçessario vos passar por la pena del talión, scilicet, si se perdiere un ánima por vuestra culpa, dar la vuestra por ella. Pues non tenéys más de una, y vos por vos solo sin ser arçobispo soys obligado al primer mandamiento, scilicet, diliges Dominum Deum tuum ex toto corde tuo et ex tota anima tua et ex tota mente tua, et proximum tuum sicut te ipsum, quia in hiis duobus mandatis universa lex pendet et prophete et cetera. Mathei $22^{55}$. Pues non tenéys con qué pagar segund las leyes de Dios, quia duo hec audivi, potestas Dei hec est, et tibi, Domine, misericordia quia tu reddes unicuique iuxta opera sua ${ }^{56}$.

E porque non se diga de vos lo que dize Christo a los phariseos: Ceci sunt et duces cecorum, cecus autem si ceco ducatum prestet, ambo in foveam cadunt. Mt $15^{57}$. E porque, muy magnífico sennor, non peresca la vuestra memoria con sonido, Ps $9^{58}$, e porque non vos podáis escusar njn llamar a enganno de ignorançia |(f. 2rb) delante Dios, al qual tomo por testigo.

(5) Commo quier que vos, sennor, seaes farto letrado e muy solícito açerca del regimjento de vuestra ánima e habundéis de muchos famosos libros de la sagrada escriptura y en vuestra curia e casa tengaes elegantes et famosos letrados, quorum corrigiam calciamentorum desatar yo non soy digno ${ }^{59}$, y tengaes personas devotas spirituales de quien recibaes e ayaes saludable consejo, coram quibus balbuciens et mutus yo me fallaría, mas porque vos, sennor, soes persona común e non particular.

E porque los santos nuestros antepassados doctores, actores de las sçiençias para nuestra consolaçión, hedificaçión e doctrina, non en vano ayan trabajado njn les seamos ingratos, en non nos querer instruyr, regir e governar por sus muy útiles consejos, pues para nosotros lo trabajaron e perdieron el suenno.

Commo quiera que todos los que escrivieron, fablaron bien e todos quisieron desir una cosa, scilicet, amar a Dios e al próximo | (f. 2va), in hiis duobus mandatis tota lex pendet et profecte. Mathei $22^{60}$, pero algunos fablaron más claro e más rracionabiliter que otros, segund más eran illuminados de graçia et segund que mas partía Dios con ellos de su bondat.

E porque lo que es bien dicho y valde directivo para la honrra de Dios e salud de las ánimas, non es rrasón quod lateat, njn sufre justiçia que sea vilipendido e menospreciado e traydo en oblivión por floxedat, negligençia o pusilanimidat, lo qual se faze quando los libros se están echados por los almarios o librerías cargados de polvo que de raro se abren o nunca.

(6) Por todo lo suso dicho, muy magnífico sennor, como fijo de obediençia summo karitatis affectu, ut supra, trabajé de vos enbiar el subseqüente tractado, el qual saqué de un libro mayor, que tracta otras muchas buenas materias. La orden del qual libro para que este tractado se pueda bien entender porné en fin deste prólogo.

Este quaderno, sennor, vos mostrará quatro cosas prinçipales: lo (f. 2vb) primero, qué soes e qué es el oficio que tenéis e en qué silla estaes assentado e quántas gradas tiene vuestro estrado; lo segundo, cómo avéys de rregir e governar el pueblo encomendado; lo terçero, qué es la cuenta que avéys a dar; lo quarto, qué es el fruto que cogeréis de buena cuenta o de mala.

(7) La causa que me movió, muy magnífico sennor, es los grandes e buenos desseos que tenéis, en espeçial tres: lo primero, onrrar e rreparar vuestra eglesia e rregir e corregir vuestros clérigos; lo segundo, dar forma a rrestituir vuestros cargos; lo terçero, fazer penitençia de commissis e abstener a futuris, ne quando rapiat et non sit qui eripiat (Ps 49,22). 
O sennor, estonçes cognosçeremos que desseades todo esto quando lo pusierdes en obra. In cassum enim desideratur corde quod opere non exequitur. Muy ligero está todo esto de fazer e acabar con Dios, si se començasse, pues que a grandes bozes la sacra escriptura sienpre nos llama a la conversión, en espeçial con una parábola | (f. 3ra) o figura del evangelio. Quando vino el sennor de la vinna e falló una figuera que nunca avía llevado fruto e como el ortelano la quisiese dissipar e arrancar e quemar, mandó gela el sennor dexar fasta otro anno e así otro anno e así otro. Luce $13 .{ }^{61}$ Esto es tres veyntenas de años que Dios espera al pecador que se convierta, et si passa la terçera sin fazer fruto de penitençia, ya non lleva remedio, ergo extirpetur et cetera, quia miseraciones eius super omnia opera eius ${ }^{62}$, nec vult Deus perire animam, sed rectractat cogitans ne penitus pereat qui abiectus est, $2^{\circ}$ Regum c. ${ }^{\circ} 14^{\circ 63}$. Derelinquit impius viam suam et cetera ${ }^{64}$. Quis scit si convertatur et ignoscat Deus et cetera ${ }^{65}$. Pero si nunca se comjença, quanto mas estoviere la llaga por curar, mas se enduresçerá o se empodresçerá e incurable se fará e mortífera.

(8) Mas, ¿qué aprovechan, sennor, que todos los amonestamientos, promissiones, falagos e amenazas de la sancta escriptura e los consejos | (f. 3rb) de los santos doctores, omnia videntur nobis quasi deliramenta, Luce $24^{66}$ ? De donde se alcança una nesçessaria conclusión, scilicet que algund artículo de la fe no creemos, y estę deve ser el postrimero, scilicet vitam eternam. ¡Guay de quien tal cree!

Bien lo leemos e farto pro manibus lo trahemos e bien lo entendemos. Nunca tantos letrados ovo después que crió Dios el mundo como oy día. Mas paresçe que non se dise a nosotros que bevimos en esta sexta hedat, salvo a los otros passados de las cinco primeras, porque agora buen Ihesu Christo nuestro hermano nós tenemos que murió por nosotros e pagó nuestras culpas.

Esta palabra lieva oy sin cuento ánimas al infierno. Verdat es que murió e pagó por las culpas passadas, mas por las futuras, después de su muerte, mors illi ultra non damnabitur ${ }^{67}$ Quien non se quisiere aprovechar de los sacramentos de la santa eglesia, nichil le aprovechará la muerte de Christo, salvo para mayor dapnaçión por la ingratitud.

(9) Desta ma|(f. 3va)teria, sennor, es otro libro, obra muy nueva, muy santa et provechosa, en que se declara todo este passo muy claro ad plenum et ad placitum y fuerte sin que nada se pueda negar. Es una obra tanto nueva que no ay sino dos en todo vuestro arçobispado; es una escriptura valde delectable e directiva; es libro que todos los onbres le avrían menester leer para que como en un espejo cognoscan cómo se salvan o se condepnan.

E para que cognoscan e vean cómo todo es vano quanto se faze debaxo de la luna, dízese vano todo aquello que caresçe de fin perpetuo e así son oy todas las obras de los fijos de los onbres, que todas peresçen sin conseguir nada a la postre, porque nescierunt neque intellexerunt, in tenebris ambulant, ideo sepulcra eorum domus illorum in eternum ${ }^{68}$.

(10) Síguese la orden del tractar del libro suso dicho.

Un actor de sciencia nuevo, grand maestro e muy illuminado de graçia, grand zelador de la honrra de Dios e salvaçión de ánimas, fizo mul (f. $3 \mathrm{vb}$ ) chos libros e diversos tractados de todas las artes e sçiençias que al humano entendimjento se pueden representar. El qual en todos los proçessos de sus libros tovo nueva manera de tractar, scilicet probando per raciones máximas todo lo que dixo, faziendo artes e invençiones muy sotiles e claras para mostrar e apre-

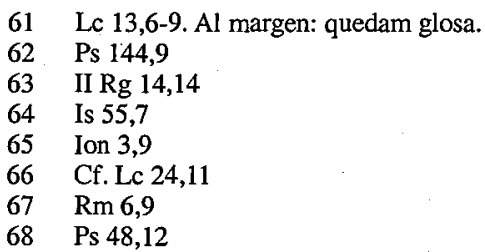


hender sus sçiençias, no curando de las actoridades de la sacra escriptura, mas fortificando e afirmando la sacra scriptura con sus razones.

Quando ya fueron senbradas sus obras e libros por los estudiantes e en muchas de sus obras quasi en todas tovo muy fuerte e agudo estilo de tractar, en tal manera que no lo entendían. Así difinido fue e acordado por muchos dellos que este actor e maestro fuese buscado e rogado que fisiese un nuevo e general tractado o libro a todas sus sçiençias de muy claro estillo para que con este se pudiesen entender todos los otros sus libros.

(11) E así | f. 4ra) fue buscado por un santo monge. E fallolo en un prado o valle de árboles çerca de un camino que venía de Roma, e fallolo muy triste e desconortado. Como se saludaron, el monje demandando ovo de saber que aquel era el maestro que él buscava. El monje le demandó por qué así estava desconortado e pensoso. Él rrespondió que porque non avía podido acabar en Rroma el santo negoçio de Ihesu Christo e la pública utilidat de toda la christiandat, por quanto el papa e sus conpañeros no le avían querido ayudar nijn oyr. Como el monje le informase de su enbaxada e le demandase el libro general suso dicho, respondió que non estava de tal propósito, por quanto aquel libro demandado era de grand trabajo e acabado de fazer aprovecharía muy poco o nada entre los christianos e su trabajo se perdería, por lo qual antes estava de voluntad de se yr a pedricar a los infieles la verdat. El monje le ovo de inportunar e mucho rrogar |f. 4rb) disiendo que mucho aprovecharía el tal libro e si agora no aprovechase, que Dios daría algund tienpo en que serían conosçidas sus obras e aprovechasen et que le fasía grand conçiençia si el dicho libro general no fisiese, como sea cosa que Dios no da su graçia de balde. E asy ovo de prometer de faser el libro.

(12) E mirando un fermoso árbol debaxo de que estava el monje, dixo el maestro: este libro será fecho a significaçión de ese árbol, scilicet, porque así como ese árbol tiene siete cosas en sí, así este libro que se llamará Arbor sciencie será conpuesto de siete cosas, scilicet, rayzes, tronco, ramas, ramuchos, fojas, flores e fruto. E non solo será un árbor, mas serán dies e seys árbores, et cada un árbor terná estas siete cosas. E los árbores son estos:

Arbor elementalis en que se tracta de los quatro elementos e de sus obras. Arbor vegetalis en que se tracta de las plantas. Arbor sensualis en que se tracta de los animales brutos. Arbor ymaginalis en que se tracta ( (f. 4va) desta potencia ymaginativa. Arbor humanalis en que se tracta del ome, así del cuerpo como del ánima. Arbor moralis, et hec est duplex, en el uno se tracta de virtutibus, en el otro de viciis. Arbor imperialis, en que se tracta qué cosa es príncipe, rey o enperador e qué es el ofiçio que tiene e cómo lo ha de rregir e qué cuenta ha de dar. Arbor apostolicalis, en que se tracta de la eglesia, del papa e sus conpañeros e súbditos, e qué cosa es o para qué es papa o perlado e del su ofiçio e regimiento. Arbor çelestialis en que se tracta de los çielos e de los cuerpos supra çelestes e sus movimientos e inpresiones. Arbor angelicalis en que se tracta de los ángeles e de su natura. Arbor eviternalis en que se tracta de dos cibdades, scilicet de parayso e infierno, e de su durar para sienpre, e este árbor es muy espantable a leer. Arbor maternalis en que se tracta de Nuestra Señora, cómo es madre de justos e pecadores, e este árbor es muy consolativo a leer. Arbor christinalis en que se tracta de Ihesu Christo e del benefiçio de la redemçión | (f. $4 \mathrm{vb}$ ) de Adam e de su linaje. Arbor divinalis en que se tracta de Dios e de sus obras interiores e de sus propiedades. Arbor exenplificabilis en que se ponen exemplos muy graçiosos e suaves hedificativos e muy plasibles a leer e mucho llenos de doctrina. Arbor questionalis en que se ponen questiones de la materia tractada e las questiones e las soluçiones della declarando mucho la escuridat de la letra tractada, e este árbor qüestional está enxerido e derramado por todos los otros.

(13) E porque, muy magnífico sennor, de todos aquestos 16 árbores aunque todos son desseables e buenos, bien llenos de doctrina e sçiençia, pero más que ninguno otro a nuestro propósito fase para vos e para vuestro ofiçio el árbol apostolical. E porque el árbol exenplifical es muy plasible e provechoso, estos dos tantum acordé con el selo suso dicho de sacar del cuerpo del libro e enbiar a vuestra sennoría. Es pues menester, señor, que por honrra de Dios e de su eglesia e provecho de vuestra ánima e de las ánimas | (f. 5ra) del pueblo a vos encomenda- 
do. E porque el trabajo e estudio de aqueste actor e maestro no caresca de fin qué es la execuçión de su doctrina, que pongáis sagás e biva oreja a oyr e depongáis terrenos cuydados que militant adversus animam ${ }^{69}$, a entender todo este quaderno. El qual vos lea un ombre bien letrado, subtil de entendimjento e persona spiritual, por que las sentençias obscuras ponga en clara plática, et no aborresca la letra por fuerte, mas léala dos o tres vezes fasta que lo entienda; ha se de leer muy apuntado, aunque en las fojas e flores del árbol apostolical non se deve mucho detener, que non fasen tanto a nuestro propósito como lo otro.

Esto se osó desir e enbiar a vuestra sennoría porque como dise ut supra: ubi maius periculum metuitur (sic), ibi diligencius et caucius succurrendum est ${ }^{70}$.

(14) Grand dolor, sennor, es que una tan grande e magnífica persona como vos, tanto pregonado e sonado por toda la tierra, tanto sublimado en el saçerdoçio, dignificado en tan | (f. $5 \mathrm{rb}$ ) alta silla secunda post apostolicam, ayaes de aver nasçido de balde e ayaes de caresçer de la fin para que fuestes criado e ayaes seydo así honrrado tan breve tiempo en la tierra para padesçer infierno in perpetuum, lo qual sin dubda tenéis aparejado, si ansí avéys de acabar vuestros días, quia nisi conversi fueritis, gladium suum vibrabit ${ }^{71}$ et cetera. E porque vos convertido qui estis lux mundi, Mathei $5^{72}$, es causa que el pueblo se convierta, et vos obstinado de nesçessario el pueblo ha de estar obstinado como veréys por el proçesso deste tractado. Conviene pues, sennor, que abiciamus opera tenebrarum et induamur armis lucis ${ }^{73}$. Conviene que desechéis e no oyaes personas aduladores e lisonjeros que son seupdoprophete, quos a fructibus eorum cognosceti ${ }^{74}$, que vos disen e consejan todo el contrario de lo que la sacra scriptura e los santos doctores disen e amonestan, disientes: «Nesçesario e cosa justa es a vuestro estado tan grand triumpho | (f. 5va) e magnifiçençia de casa conpuesta de tantos gentiles onbres de grand linaje, ricos muy vestidos e ponposos, menester avéis para defender vuestro estado tantos onbres de armas e de otros cavallos, cosa rrazonable es que abondéis vuestra casa de sobrados gastos e preçiados manjares e traeres, e los conbites e presentes o salas que fisieredes, fagaes muy sumptuosos que suenen por toda la tierra, que todo esto rrequiere vuestra dignidat, pues que lo sufre vuestra renta, et aún que demandés prestado a vuestros vasallos para ello». No vos disen, señor, la verdat, que todo eso que es superfluo, por entero es de los pobres que mueren e peresçen de fanbre e de frío e no lo sabe ninguno sino Dios e ellos que lo padescen.

E si, sennor, dixeredes que los tales consejeros son letrados, en el tremendo judicio, scilicet, quando venerit dies Domini magnus, dies illa, dies ire, dies tribulacionis et angustie, dies calamitatis et miserie, dies tenebrarum et caliginis, dies ne $\mid(f .5 \mathrm{vb})$ bule et turbinis, dies tube et clangoris super civitates munitas et super angulos excelsos, Sophonie $1^{\circ 75}$, si con ellos vos escusaredes, vos será respondido: surgant et opitulentur vobis, et in necessitate vos protegant, Deutero $32^{76}$. Facite ergo, sennor, dignum fructum penitencie, Mathei $3^{\circ 77}$, dum tempus habetis, et restituite a Dios saltem in voto.

(15) Tandem, venerande presul, si toxicata linga dixerit michi quispiam: quare tu, folium quod vento raperis ${ }^{78}$, talia ad tantum pontificem et dominum sic inverecunde ausus es profferre verba, satisfaciam illi dicens: non scripsi hec sicut servus ad dominum, sicut subditus ad

I Ptr 2,11

Cf. nota 48 .

Ps 7,13

Mt 5,14

$\operatorname{Rm} 13,12$

Mt 7,16

Soph $1,14.15-16$

Dt 32,38

Mt 3,8

78 Cf. Iob 13,25 
prelatum nec sicut filius ad patrem, sed ablacta seu salva omni eius status dignitate, sacerdocii sublimitate personeque reverencia, perfeccione religionis et vite sanctitate, sicut creatura ad creaturam, sicut homo ad hominem, sicut Plato ad Ciceronem. Deo gracias.

(16) | (f. 6ra) Todo este libro destos diez e seys árbores está en rromançe, e así saqué yo este quaderno en romançe. E por tanto yo fize este prólogo en romançe, el qual se somete a toda fraterna e honesta correcçión.

Klaus Reinhardt

Institut für Cusanus-Forschung an der Universität un der Theologischen Fakultät Trier

Domfreihof 3

D-54290 Trier

E-mail: reinhard@uni-trier.de 